Systematic Review

\title{
Palmitoylethanolamide, a Special Food for Medical Purposes, in the Treatment of Chronic Pain: A Pooled Data Meta-analysis
}

Antonella Paladini, MD, PhD ${ }^{1}$, Mariella Fusco, PhD², Teresa Cenacchi, MD, PhD²,

Carlo Schievano, $\mathrm{PhD}^{4}$, Alba Piroli, MD, $\mathrm{PhD}^{5}$, and Giustino Varrassi, MD, $\mathrm{PhD}^{6}$

From: ${ }^{1}$ Assistant Professor, Department of Anesthesia and Pain Medicine, MESVA, University of L'Aquila, L'Aquila, Italy; ${ }^{2}$ Scientific Information and documentation, Epitech Research

Group, Via Luigi Einaudi 13, Padova, Italy; ${ }^{3}$ Clinical Research Advisor, Epitech Research Group, Via Luigi Einaudi 13, Padova, Italy; ${ }^{4}$ Adjunct Professor of Statistics,

Department of Comparative Biomedicine, University of Padova, Padova, Italy; ${ }^{5}$ Assistant Professor, Department of Anesthesia and Pain Medicine, MESVA, University of L'Aquila, L'Aquila, Italy; ${ }^{6}$ Full Professor of Anesthesia and Pain Medicine, University of L'Aquila, L'Aquila, Italy

Address Correspondence: Giustino Varrassi, MD, PhD Full Professor Anesthesia and Pain Medicine University of L'Aquila L'Aquila, Italy

President of the Paolo Procacci Foundation Via Tacito 7 00193 Roma, Italy

E-mail: giuvarr@gmail.com

Disclaimer: There was no external funding in the preparation of this manuscript. Conflict of interest: Each author certifies that he or she, or a member of his or her immediate family, has no commercial association (i.e., consultancies, stock ownership, equity interest, patent/licensing arrangements, etc.) that might pose a conflict of interest in connection with the submitted manuscript.

Manuscript received: 05-01-2015 Revised manuscript received: o8-13-2015

Accepted for publication: 08-18-2015

Free full manuscript: www.painphysicianjournal.com
Background: A growing body of evidence suggests that neuroinflammation, which is characterized by infiltration of immune cells, activation of mast cells and glial cells, and production of inflammatory mediators in the peripheral and central nervous systems, has an important role in the induction and maintenance of chronic pain. These findings support the notion that new therapeutic opportunities for chronic pain might be based on anti-inflammatory and pro-resolving mediators that act on immune cells, in particular mast cells and glia, to mitigate or abolish neuroinflammation. Among anti-inflammatory and pro-resolving lipid mediators, palmitoylethanolamide (PEA) has been reported to down-modulate mast cell activation and to control glial cell behaviors.

Objective: The aim of this study was to perform a pooled meta-analysis to evaluate the efficacy and safety of micronized and ultra-micronized palmitoylethanolamide (PEA) on pain intensity in patients suffering from chronic and/or neuropathic pain.

Study Design: Pooled data analysis consisting of double-blind, controlled, and open-label clinical trials.

Methods: Double-blind, controlled, and open-label clinical trials were selected consulting the PubMed, Google Scholar, and Cochrane databases, and proceedings of neuroscience meetings. The terms chronic pain, neuropathic pain, and micronized and ultra-micronized PEA were used for the search. Selection criteria included availability of raw data and comparability between tools used to diagnose and assess pain intensity. Raw data obtained by authors were pooled in one database and analyzed by the Generalized Linear Mixed Model. The changes in pain over time, measured by comparable tools, were also assessed by linear regression post-hoc analysis and the Kaplan-Meier estimate.

Twelve studies were included in the pooled meta-analysis, 3 of which were double-blind trials comparing active comparators vs placebo, 2 were open-label trials vs standard therapies, and 7 were open-label trials without comparators

Results: Results showed that PEA elicits a progressive reduction of pain intensity significantly higher than control. The magnitude of reduction equals 1.04 points every 2 weeks with a 35\% response variance explained by the linear model. In contrast, in the control group pain, reduction intensity equals 0.20 points every 2 weeks with only $1 \%$ of the total variance explained by the regression. The Kaplan-Meier estimator showed a pain score $\leq 3$ in $81 \%$ of PEA treated patients compared to only $40.9 \%$ in control patients by day 60 of treatment. PEA effects were independent of patient age or gender, and not related to the type of chronic pain.

Limitations: Noteworthy, serious adverse events related to PEA were not registered and/or reported in any of the studies.

Conclusion: These results confirm that PEA might represent an exciting, new therapeutic strategy to manage chronic and neuropathic pain associated with neuroinflammation.

Key words: Chronic pain, neuropathic pain, neuroinflammation, astrocytes, glia, mast cells, microglia, micronized and ultra-micronized palmitoylethanolamide

Pain Physician 2016; 19:11-24 
hronic pain affects many people in the Western world, constituting an enormous burden for the individuals and society $(1,2)$. According to the American Pain Society, the prevalence of chronic pain in the US is $35.5 \%$ (3). Chronic inflammatory pain may result from tissue injury, such as osteoarthritis or rheumatoid arthritis (4). Neuropathic pain is caused by a lesion or disease affecting the somatosensory system $(5,6)$. Worth noting, pain associated with chronic inflammatory/autoimmune disorders such as rheumatoid arthritis also exhibits a neuropathic component $(7,8)$. Similarly, neuropathic pain is usually associated with activation of immune cells $(8,9)$.

Treating chronic pain is challenging. Current pharmacological treatments comprise an array of drug classes including anticonvulsants, antidepressants, opioids, acetyl-para-aminophenol (APAP), non-steroidal anti-inflammatory drugs (NSAIDs), and analgesics $(10,11)$. Nevertheless, the available therapies provide incomplete pain relief, and predictable treatmentrelated side effects are common and resolved with supervision (10). The identification of safe and efficacious treatments for chronic pain remains a major worldwide public health need.

As pain signals and their processing are performed by neurons, the majority of current therapies target neurons. However, in chronic pain the somatosensory system is not the only protagonist. A growing body of evidence suggests that neuroinflammation, which is characterized by infiltration of immune cells, activation of mast cells and glial cells, and production of inflammatory mediators in the peripheral and central nervous systems, has an important role in the induction and maintenance of chronic pain (12-14). Chronic neuroinflammation is sustained by an imbalance between pro-inflammatory and pro-resolving mediators (15-17). These findings support the notion that new therapeutic opportunities for chronic pain might be based on antiinflammatory and pro-resolving mediators that act on immune cells, in particular mast cells and glia, to mitigate or abolish neuroinflammation $(15,17)$.

Among anti-inflammatory and pro-resolving lipid mediators, palmitoylethanolamide (PEA) has been reported to down-modulate mast cell activation $(18,19)$ and to control glial cell behaviors (20-22). PEA is an acylethanolamide widely distributed in different tissues, including nervous tissues, and is synthesized on demand (23). Endogenous levels of PEA are altered following stress or injury and/or pain (24). Systemic or local alterations of PEA levels have been reported in clinical conditions associated with pain (25-28). Numerous preclinical studies demonstrate the ability of PEA to reduce inflammation and pain induced by various acute stimuli (29). The effect of PEA administration is dose-dependent (30-34). The anti-inflammatory and analgesic effects of PEA have been confirmed in models of chronic inflammation $(35,36)$ and chronic or neuropathic pain (22,36-39). In these models, chronic treatment with PEA not only reduced pain but also preserved peripheral nerve morphology, reduced endoneural edema, the recruitment and activation of mast cells, and the production of pro-inflammatory mediators at the injury site $(22,37,38)$. Taken together, these experimental data indicate that PEA, via regulation of persistent inflammatory processes, can directly intervene in nervous tissue alterations responsible for pain, i.e., to act as a disease-modifying agent (39).

In the last few years, a growing number of clinical studies have confirmed the pain-relieving properties of PEA, in different chronic pain conditions $(40,41)$. This prompted us to carry out a pooled meta-analysis based on data available from clinical trials with the aim of evaluating the efficacy and safety of micronized and ultra-micronized PEA on pain intensity reduction in relation to age and etiology of pain in patients with chronic pain and/or neuropathic pain.

\section{Methods}

A systematic search was carried out to identify all clinical trials conducted between 2010 (year of the first clinical trials on micronized and ultra-micronized m.PEA- u.m.PEA) and 2014 where PEA (Normast ${ }^{\circledR}$, Epitech Group, Saccolongo, Italy) had been used, consulting databases (PubMed, Medline, Google Scholar, Cochrane) and proceeding of congresses in neuroscience. The search strategy included the terms: chronic pain, neuropathic pain, micronized and ultra-micronized palmitoylethanolamide, and their combination.

The criteria adopted for selection of clinical studies to be included in the meta-analysis protocol were based on the following parameters:

i) Comparability between studies for pain criteria, regardless of disease etiology;

ii) Similarity between the tools used to assess pain intensity;

iii) Availability of all raw data, provided by the corresponding authors of identified papers after clear request to the corresponding author.

In some studies, pain was assessed utilizing the 
Visual Analogue Scale (VAS, $0-100 \mathrm{~mm}$, in $0-10 \mathrm{~cm}$ segments); in other studies, the Numeric Rating Scale (NRS, 0 - 10 points - considered the numerical version of the VAS) was used. Moreover, studies were selected regardless of PEA dosage used and duration of treatment. Evaluation times that exceeded 60 days were excluded from the analysis due to lack of data and risk of a leverage effect. Only $1.4 \%$ of data reported in the analyzed papers would have exceeded this cutoff. In case the cutoff would have been reduced to 30 days of observation, the loss of data would have increased to $17.9 \%$. The threshold of pain intensity at baseline was $\geq 4$ (NRS/ VAS); this score has been one of the inclusion criteria used in most of the considered protocols. Patients with baseline analysis only and without other measurements were excluded from the study. Furthermore, to avoid too many follow-up classes, given that the number and times of assessment differed across the various studies, observation times were grouped as follows: T0 (baseline), T1 (seventh - tenth day), T2 (eleventh - fourteenth day), T3 (fifteenth - twenty-first day), T4 (twenty-second - forty-fifth day), and T5 (forty-sixth - sixtieth day). The available raw data were assembled in one database and analyzed as if they were the results from one single study. The protocol of this pooled clinical data was planned to take advantage of pooling data. The principal aim was to analyze in a single overall assessment the data of PEA efficacy, otherwise fragmented between the results of several clinical studies, testing differences of effect on pain treatment with PEA, in association with standard therapies, compared to treatment with placebo and/or conventional analgesic therapies alone in the control group.

Evaluation of efficacy variability as a function of time and tolerability was also included. Given the availability of raw data, pain reduction over time was assessed through a pooled data evaluation, adopting as analysis method the Generalized Linear Mixed Model (GLMM). This analysis model allows to correctly consider the within-subject variance and the presence of missing values. While this approach may be viewed as more speculative and less "traditional," we believe it adds value to an eventual positive outcome. In order to account for the different effects of PEA present between open and double-blind studies, this analysis model always included the "double-blind" variable, so as to evaluate pain reduction net of the placebo effect.

The initial analysis was performed using all data, including those where pain intensity at baseline was < 4 (NRS/VAS). The reduction of pain was assessed based on treatment, study type (blind or open), baseline pain intensity, and their possible interactions.

The second analysis considered only patients with pain intensity $\geq 4$ (NRS/VAS) with inclusion of age (< 65 years and $\geq 65$ years), gender (M/F), and etiology of pain as co-variants. Pain reduction over time was assessed by linear regression post-hoc analysis. In parallel, treatment efficacy was assessed also in terms of speed in achieving a beneficial effect of PEA as compared to control group. A threshold score of $\leq 3$ (NRS/NAS) was considered to represent an efficacious reduction in pain, because literature reports this as a tolerable pain. As this necessarily implies variability in time, we used the number of days corresponding to follow-up from when the event was observed. A survival analysis according to the Cox model was used to evaluate the effect of gender, age, etiology, and study design as determinants in achieving the $\leq 3$ NRS/VAS threshold. Data analyses were performed using SAS 9.2 (SAS Institute Inc., Cary, NC, USA).

\section{Results}

Our search identified 26 clinical trials, published or unpublished, of which 12 met the inclusion criteria. Among these, 3 studies were conducted as doubleblind, randomized, controlled vs placebo, 2 were openlabel, controlled, randomized vs standard therapies, while the remaining 7 were open-label, without control (Table 1 and Table 2).

The patients included in the meta-analysis (Table 1)

Table 1. Patient characteristics.

\begin{tabular}{|c|c|c|c|c|c|c|c|c|c|}
\hline & \multicolumn{2}{|c|}{ Study Design } & \multicolumn{2}{|c|}{ Gender } & \multicolumn{2}{|c|}{ Age (years) } & \multicolumn{2}{|c|}{ Pain Intensity (baseline) } & \multirow{2}{*}{ TOTAL } \\
\hline & Open Label & Double-blind & Male & Female & $<65$ & $\geq 65$ & $<4$ & $\geq 4$ & \\
\hline Control & 30 & 266 & 138 & 158 & 251 & 45 & 18 & 278 & $\begin{array}{c}296 \\
(20 \%)\end{array}$ \\
\hline m.PEA / u.m.PEA & 703 & 485 & 460 & 708 & 742 & 446 & 35 & 1153 & $\begin{array}{c}1188 \\
(80 \%)\end{array}$ \\
\hline TOTAL & $\begin{array}{c}733 \\
(49 \%)\end{array}$ & $\begin{array}{c}751 \\
(51 \%)\end{array}$ & $\begin{array}{c}598 \\
(41 \%)\end{array}$ & $\begin{array}{c}866 \\
(59 \%)\end{array}$ & $\begin{array}{c}993 \\
(67 \%)\end{array}$ & $\begin{array}{c}491 \\
(33 \%)\end{array}$ & $\begin{array}{c}53 \\
(4 \%)\end{array}$ & $\begin{array}{c}1431 \\
(96 \%)\end{array}$ & 1484 \\
\hline
\end{tabular}


Table 2. Clinical trials selected for pooled meta-analysis.

\begin{tabular}{|c|c|c|c|c|c|}
\hline Source of pain & Study Design & $\mathrm{n}^{\circ}$ & $\begin{array}{l}\text { Regimen of m.PEA or } \\
\text { u.m.PEA }\end{array}$ & $\begin{array}{l}\text { Published } \\
\text { Studies and } \\
\text { Proceedings }\end{array}$ & $\begin{array}{l}\text { Unpublished } \\
\text { Studies }\end{array}$ \\
\hline Lumbosciatica & $\begin{array}{l}\text { Double blind, two doses, } \\
\text { randomized, controlled } \\
\text { m.PEA vs placebo } \\
\text { + NSAIDs } \\
\text { when needed }\end{array}$ & 636 & $\begin{array}{l}1 \text { st arm } 300 \mathrm{mg} / \text { day m.PEA x } \\
21 \text { days } \\
2 \text { nd arm } 600 \mathrm{mg} / \text { die m.PEA } \\
\text { x } 21 \text { days } \\
\text { +NSAIDs when needed }\end{array}$ & $\begin{array}{l}\text { Guida G et al. } \\
2010(42)\end{array}$ & \\
\hline $\begin{array}{l}\text { Carpal tunnel syndrome in } \\
\text { diabetic patients }\end{array}$ & $\begin{array}{l}\text { Open controlled randomized } \\
\text { m.PEA vs } \\
\text { no treatment }\end{array}$ & 40 & $1200 \mathrm{mg} /$ day m.PEA x 60 days & $\begin{array}{l}\text { Assini A et al. } \\
2010(68)\end{array}$ & \\
\hline $\begin{array}{l}\text { Carpal tunnel syndrome- } \\
\text { course pre-and post-operative }\end{array}$ & $\begin{array}{l}\text { Open controlled randomized } \\
\text { u.m.PEA vs no treatment }\end{array}$ & 50 & $\begin{array}{l}1200 \mathrm{mg} / \text { day u.m.PEA x } 60 \\
\text { days }\end{array}$ & & $\begin{array}{l}\text { Evangelista M. } \\
\text { 2015a }\end{array}$ \\
\hline Carpal tunnel syndrome & $\begin{array}{l}\text { Double blind, randomized, } \\
\text { controlled u.m.PEA vs placebo } \\
\text { + NSAIDs } \\
\text { when needed }\end{array}$ & 48 & $\begin{array}{l}1200 \mathrm{mg} / \text { day u.m.PEA x } 30 \\
\text { days + NSAIDs } \\
\text { when needed }\end{array}$ & & $\begin{array}{l}\text { Zanette G } \\
\text { 2015b }\end{array}$ \\
\hline $\begin{array}{l}\text { Radiculopathy (331) } \\
\text { Osteoarthritis (54) } \\
\text { Herpes Zoster (44) } \\
\text { Diab. Neuropaty (32) } \\
\text { Failed back surgery (76) } \\
\text { Oncologic (22) } \\
\text { Other diseases (51) }\end{array}$ & Open-label & 610 & $\begin{array}{l}\text { 1200mg/day u.m.PEA } \\
\text { x } 21 \text { days followed by } 600 \mathrm{mg} / \\
\text { day u.m.PEA x } 30 \text { days } \\
\text { (+anticonvulsant, opioid } \\
\text { and rescue drugs* except } 90 \\
\text { patients) }\end{array}$ & $\begin{array}{l}\text { Gatti A et al. } \\
2012(69)\end{array}$ & \\
\hline Low back pain & Open-label & 20 & $\begin{array}{l}\text { 1200mg/day u.m.PEA } \\
+ \text { Oxyicodone x } 30 \text { days }\end{array}$ & \begin{tabular}{|l} 
Desio P. \\
$2011(70)$
\end{tabular} & \\
\hline $\begin{array}{l}\text { Diabetic neuropathy (11) } \\
\text { Postherpetic neuralgia (19) }\end{array}$ & Open-label & 30 & $\begin{array}{l}\text { 1200mg/day u.m.PEA } \\
\text { +Pregabalin } \mathrm{x} 45 \text { days }\end{array}$ & \begin{tabular}{|l} 
Desio P. \\
$2010(71)$
\end{tabular} & \\
\hline $\begin{array}{l}\text { Diabetic neuropathy,(23) } \\
\text { Traumatic neuropathy (7) }\end{array}$ & Open-label & 30 & $\begin{array}{l}1200 \mathrm{mg} / \text { day u.m.PEA x } 40 \\
\text { days }\end{array}$ & $\begin{array}{l}\text { Cocito D et al. } \\
2014(72)\end{array}$ & \\
\hline Post stroke & $\begin{array}{l}\text { Open controlled, randomized, } \\
\text { u.m.PEA + Physiotherapy vs } \\
\text { only Physiotherapy }\end{array}$ & 20 & $\begin{array}{l}\text { 1200mg /day u.m.PEA } \\
\text { x } 60 \text { days followed by } 600 \mathrm{mg} / \\
\text { day u.m.PEA x } 30 \text { days }\end{array}$ & $\begin{array}{l}\text { Parabita M et } \\
\text { al. } 2011(73)\end{array}$ & \\
\hline $\begin{array}{l}\text { Neuropathic pain induced by } \\
\text { chemotherapy }\end{array}$ & Open label & 10 & $\begin{array}{l}1200 \mathrm{mg} / \text { day u.m.PEA } \\
\text { x } 60 \text { days }\end{array}$ & & $\begin{array}{l}\text { Spada S. } \\
2015 c\end{array}$ \\
\hline Multiple Sclerosis & $\begin{array}{l}\text { Double blind, randomized, } \\
\text { controlled u.m.PEA vs placebo }\end{array}$ & 27 & $\begin{array}{l}600 \mathrm{mg} / \text { day u.m.PEA } \\
\text { x } 365 \text { days }\end{array}$ & $\begin{array}{l}\text { Montella S et } \\
\text { al., } 2014(74)\end{array}$ & \\
\hline Charcot Marie Tooth & Open label & 12 & $\begin{array}{l}1200 \mathrm{mg} / \text { day u.m.PEA } \\
\mathrm{x} 80 \text { days }\end{array}$ & & $\begin{array}{l}\text { Putzu GA. } \\
\text { 2015d. }\end{array}$ \\
\hline
\end{tabular}

a. Department of Anesthesia and Intensive Care, Catholic University, Roma, Italy. Manuscript in preparation. b. Researcher affiliation: Section of Neurology, Pederzoli Hospital, Peschiera del Garda Verona, Italy. Manuscript in preparation. c. Division of medical oncology. Hospital "Rizzo,"

Siracusa, Italy. Manuscript submitted to Pain Medicine. d. Neurology and Clinical Neurophysiology, Casa di Cura Polispecialistica Sant'Elena, Cagliari, Italy. Manuscript submitted to Journal of Pain Management.

${ }^{\star}$ rescue drugs $=$ Paracetamol + Tramadol

were 1,484, with full evaluation and at least one followup. Of these, 1,188 patients were treated with m.PEA or u.m.PEA for periods of 21 to 60 days with daily doses ranging from 300 to $1200 \mathrm{mg}$. Patients already taking standard analgesic and/or anti-inflammatory medicines received PEA in addition to the treatment provided in the protocol (Table 2). Among them, 90 received only u.m.PEA as monotherapy because they had stopped their ongoing therapy due to severe side effects. The remaining 296 patients belonging to the control group were treated with placebo and/or standard therapies (Table 2). Pain etiology was as follows: degenerative type in 1,174 patients (failed back surgery, back disorders, carpal tunnel syndrome); neuropathic in 170 patients (brachial plexus injury, diabetic, post-herpetic neuropathies, stroke); mixed in 82 patients (oncologic 
Palmitoylethanolamide in the Treatment of Chronic Pain: A Pooled Data Meta-Analysis

Table 3. Distribution of patients according to pain etiology.

\begin{tabular}{|l|c|c|c|c|}
\hline \multirow{2}{*}{} & \multicolumn{3}{|c|}{ Etiopathogenesis } \\
\cline { 2 - 5 } & Degenerative & Neuropathic & Mixed & Miscellaneous \\
\hline \multirow{2}{*}{ Patient number } & 1174 & 170 & 82 & 58 \\
& $(79.1 \%)$ & $(11.5 \%)$ & $(5.5 \%)$ & $(3.9 \%)$ \\
\hline
\end{tabular}

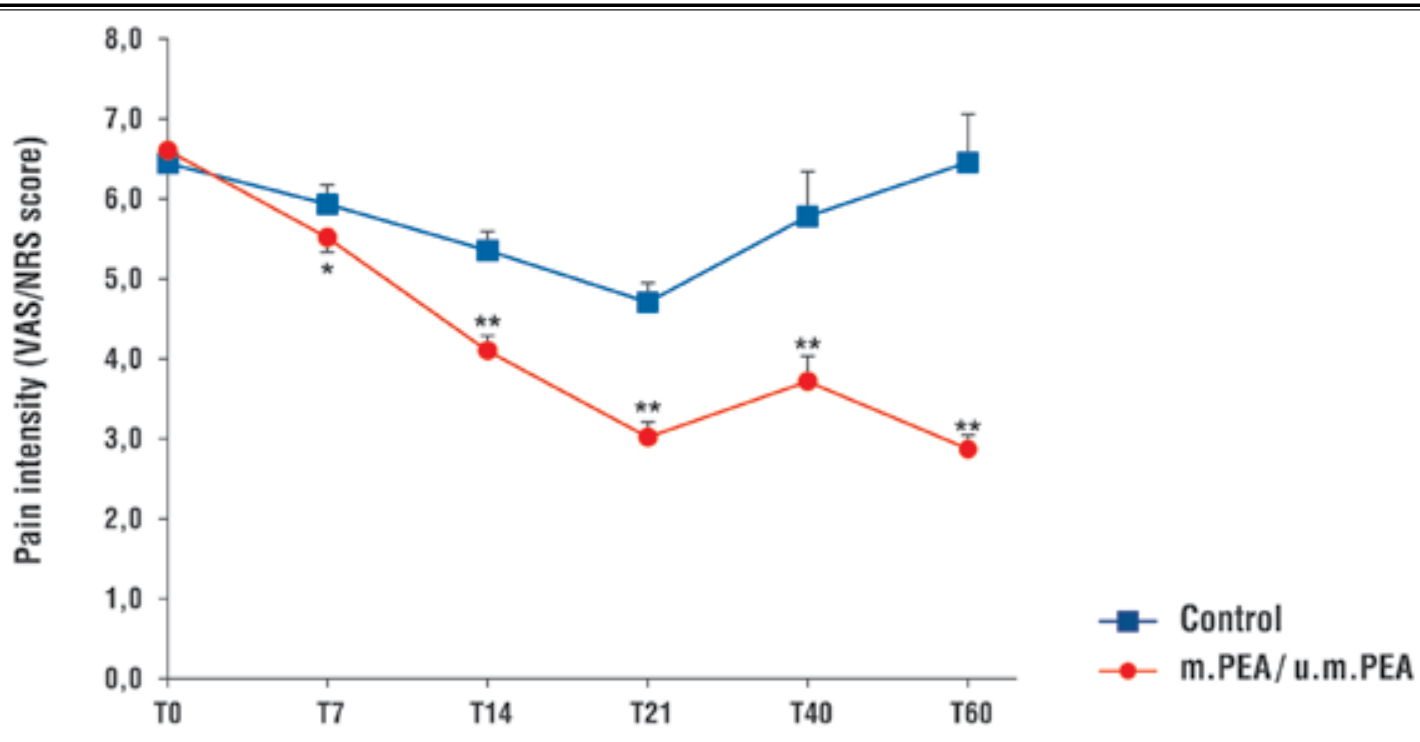

Observation Times

\begin{tabular}{ccccccc} 
& T0 & T1 & T2 & T3 & T4 & T5 \\
\hline$\Delta^{*}$ & $-0,16$ & 0,46 & 1,21 & 1,65 & 3,34 & 3,52 \\
$\mathbf{p}$ & 0,9738 & 0,0492 & $<0,001$ & $<0,0001$ & $<0,0001$ & $<0,0001$
\end{tabular}

$\Delta^{*}=$ Efficacy estimate. $\mathrm{m}$. PEA / u.m.PEA groups vs control group

${ }^{*} P<0.05$

${ }^{* *} P<0.0001$

Tukey adjusted test. Efficacy estimate net of effect due to treatment type (open or blind) and to baseline pain intensity $(<4$ or $\geq 4)$.

Fig. 1. Changes in pain intensity in patients treated with PEA and control groups at different observation times. Values are expressed as mean $\pm S E M$.

patients, arthrosis); miscellaneous (a grouping of several diseases of very different etiologies) in 58 patients (Table 3).

All observations on the intensity of pain $(4,435)$ relating to 1,484 patients were analyzed by repeated measures GLMM, using as descriptive variables: study type, baseline pain intensity, time, and treatment. The reduction in pain was present in both the PEA treated and control groups, and was significant over time $(P$
$<0.0001)$. These reductions in pain were always influenced by both the type of study $(P<0.0007)$ and baseline pain intensity $(P<0.0038)$. Pain reduction was more evident in the group treated with PEA compared to controls: the difference between the 2 groups was already significant at T1 $(P<0.05)$ and increased with continued treatment over time $(P<0.0001)$ (Fig. 1).

Reduction in pain intensity over time in both the PEA treated patients and control groups was also as- 

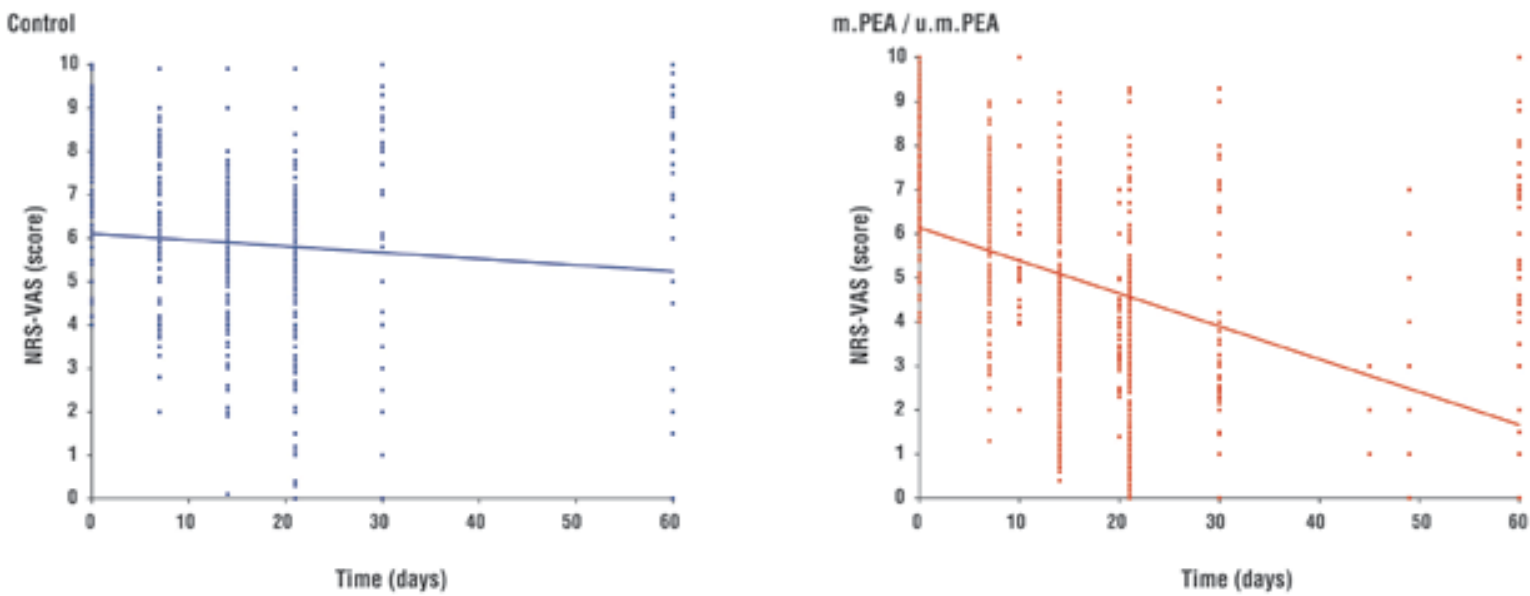

\begin{tabular}{lc|c|c|c} 
& \multicolumn{2}{c}{ CONTROL } & \multicolumn{2}{c}{ m. PEA / u.m.PEA treated } \\
Observations & 969 & & 3302 & P \\
\hline R2-Adjusted & 0,0094 & 0,0014 & 0,3511 & $<0,0001$ \\
\hline Intercept & 6,10537 & $<0,0001$ & 6,1 & $<0,0001$ \\
\hline Coefficent: daily pain reduction & $-0,01451$ & 0,0014 & $-0,074$ & $<0,0001$ \\
\hline Reduction every two weeks & 0,20 & & 1,04 &
\end{tabular}

Fig. 2. Linear regression of pain intensity score over treatment in the control and PEA treated patients groups.

sessed by linear regression analysis, excluding 53 patients who had a baseline pain intensity $<4$ (Fig. 2). This analysis confirmed the significant difference $(P<$ 0.0001 ) between the 2 groups for reduction of pain intensity as assessed by GLMM. The decrease in pain intensity in the control group was significant $(P=0.0014)$ and corresponds to a reduction of 0.20 points (NRS/ VAS) every 2 weeks, but only $1 \%$ of the total variance is explained by the regression ( $R 2$ adjusted $=0.0094-$ Fig. 2: Control). In the group treated with PEA, however, the significant reduction in pain $(P<0.0001)$ was equal to 1.04 points (NRS/NAS) every 2 weeks; the percent variance explained by regression analysis is over 35\% (= R2 adjusted 0.3511- Fig. 2: PEA treated patients).

We then examined what would be the effect, if any, of including the variables of age ( $<65$ and $\geq 65$ years), gender, and etiology in the GLMM analysis. Only 1,431 patients with initial pain intensity $\geq 4$ were considered. The results of this second analysis indicate that average pain intensity score changes over time, regardless of treatment group $(P<0.0001)$. The PEA treated and control groups were homogeneous both for intensity of pain and for all other co-variants considered. Treat- ment time with PEA produced a significant benefit ( $P$ $<0.0001$ ); the intensity of pain was also modified over time, regardless of the other variables, in particular, gender $(P<0.0035)$ (Fig. 3), etiology $(P<0.0136)$ (Fig. $4)$, age $(P<0.0001)$ (Fig. 5), and type of study $(P<$ $0.0001)$. Only age and type of study showed a different effect on treatment over time. Regarding age, for the PEA treated group at no time was there a significant difference between the under-65 and over-65 groups.

Regression analysis carried out only on patients in the PEA treated group and with baseline pain $\geq 4$ clearly shows that reduction of pain in this group was highly significant $(P<0.0001)$ both in patients aged $<65$ years and those aged $\geq 65$ years. The pain reduction corresponds to 1.17 points (NRS/VAS) every 2 weeks with a percentage of explained variance of $31 \%$ in $<65$ years group, and 1.01 points (NRS/VAS) every 2 weeks with an explained variance of $47 \%$ in the $\geq 65$ years group (Fig. 6). A survival analysis according to the Cox model was carried out to assess which factors can influence reduction in pain intensity to a value of $\leq 3$. In addition to the significant effect of treatment with PEA, a moderate effect of age and gender favored male patients aged 


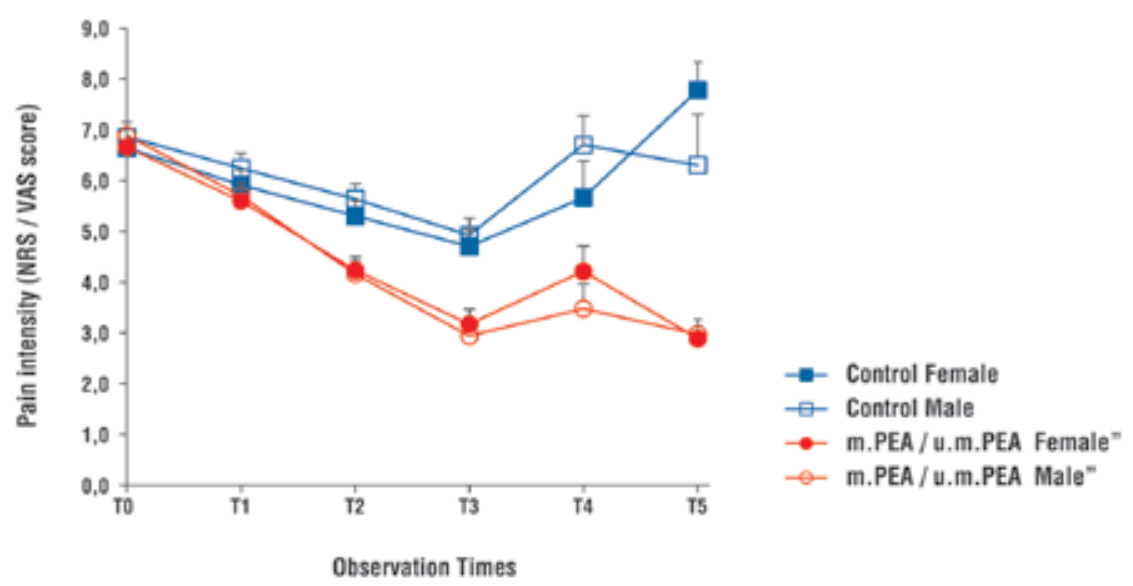

\begin{tabular}{|c|c|c|c|c|c|c|c|}
\hline \multirow[t]{2}{*}{ Groups } & \multirow[t]{2}{*}{ Gender } & \multicolumn{6}{|c|}{ Number of patiens at each cbservation time } \\
\hline & & To & $\mathrm{T1}$ & T2 & T3 & T4 & T5 \\
\hline \multirow{2}{*}{ Control } & Female & 152 & 101 & 101 & 101 & 36 & 25 \\
\hline & Male & 126 & 99 & 99 & 99 & 14 & 16 \\
\hline \multirow{2}{*}{ m. PEA / u.m.PEA } & Female & 653 & 216 & 189 & 203 & 71 & 423 \\
\hline & Male & 424 & 249 & 219 & 235 & 50 & 178 \\
\hline
\end{tabular}

Fig. 3. Average change in pain intensity by group (Control and PEA treated patients) and gender, at different time points ( $P<$ $0.0035)$. Values are expressed as mean \pm SEM.

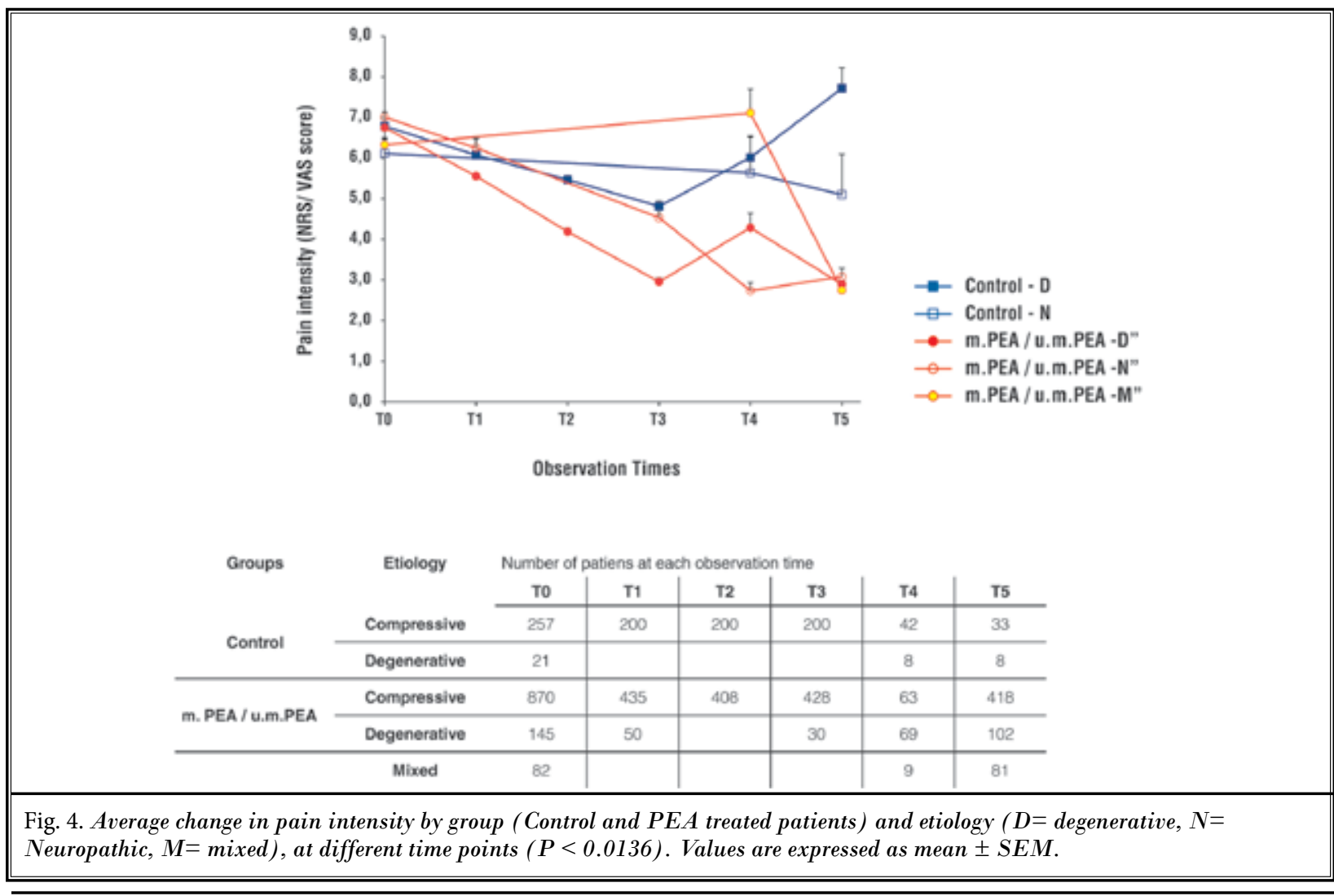



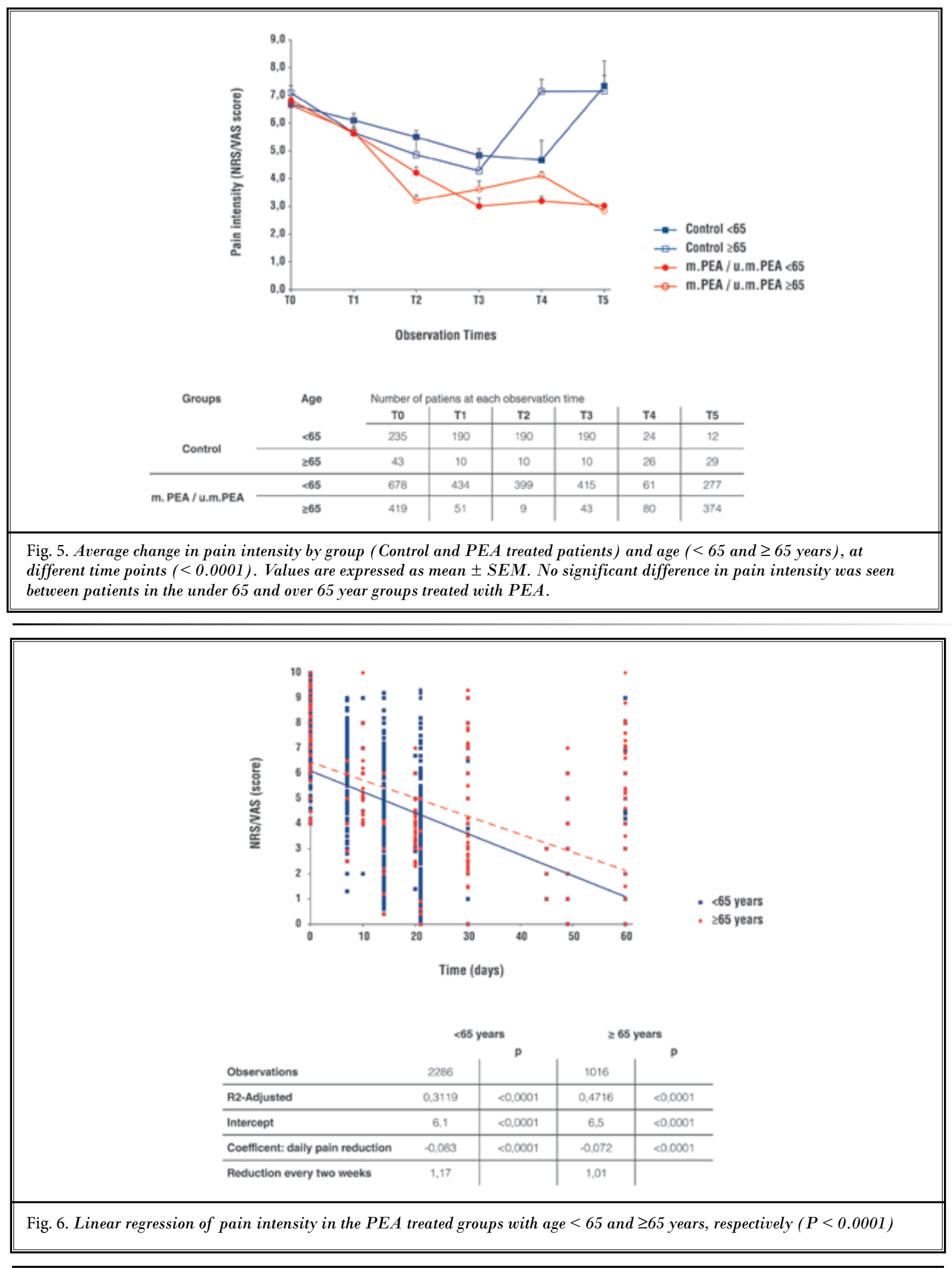
$<65$ years. The placebo effect was confirmed from the clear improvement in favor of double-blind studies regardless of treatment. The results obtained are shown in Table 4.

Analysis carried out using the Kaplan-Meier estimator on control and PEA treated groups (Fig. 7) shows, at 60 days, an estimate of achievement for a pain score $\leq$ 3 equal to $81.8 \%$ in the PEA treated group $(P<0.0001)$ compared to $40.9 \%$ in the control group. The maximum effect occurs around the fiftieth day with a median time of 49 days in the treated group, while in the control group it was estimated as greater than 60 days after the last observations. Regarding age (Fig. 8), patients older than 65 years in both groups had a lower estimate. In fact, the estimate of achievement of a pain threshold $\leq 3$ was $77.4 \%$ in the PEA treated group against $23.2 \%$ in the control group.

Hematology, blood chemistry, and urine analyses, together with a complete and accurate clinical examination carried out at baseline and at treatment end

Table 4. Determinants of improvement.

\begin{tabular}{|l|c|c|c|}
\hline Factor & Hazard ratio & Confidence interval 95\% & $\boldsymbol{P}$ \\
\hline PEA treated group vs Control group & 3.5 & $2.62-4.67$ & $<0.0001$ \\
\hline Double-blind vs Open-label studies & 4.0 & $3.31-4.76$ & $<0.0001$ \\
\hline Patients $<$ 65 vs Patients $\geq 65$ & 1.6 & $1.37-4.90$ & $<0.0001$ \\
\hline Males vs Females & 1.2 & $1.03-1.39$ & 0.0166 \\
\hline Etiology Degenerative vs Etiology Neuropathic & 0.9 & $1.14-0.79$ & 0.3131 \\
\hline Etiology Neuropathic vs Etiology Mixed & 1.1 & $0.79-1.48$ & 0.6201 \\
\hline
\end{tabular}

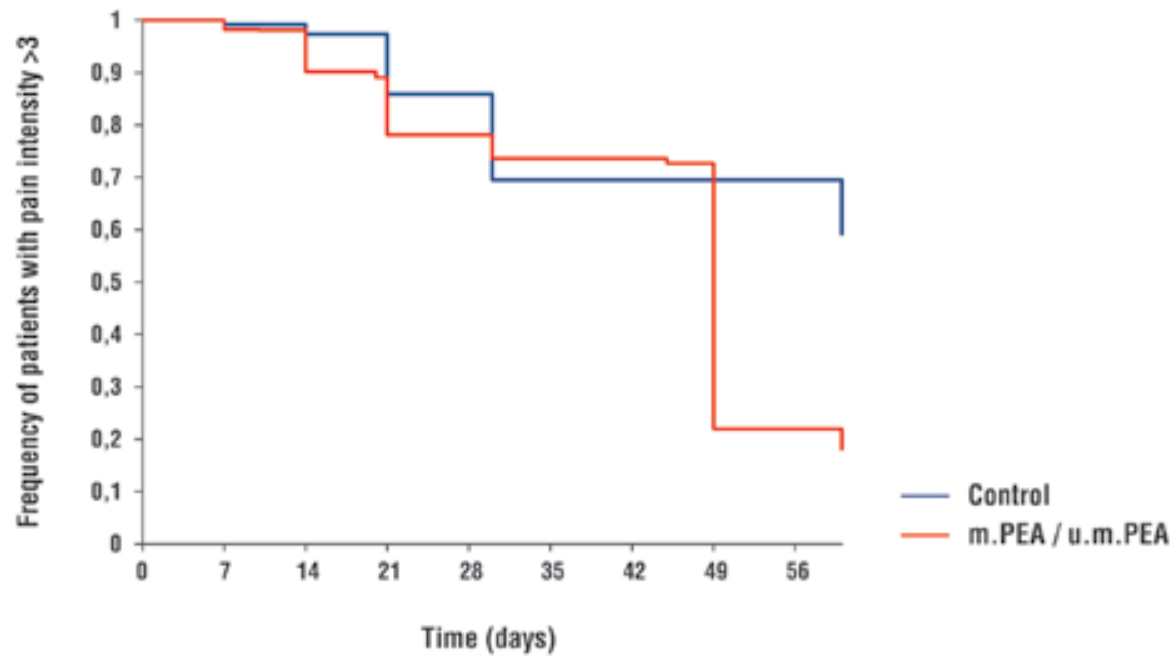

\begin{tabular}{c|c|c|c|c|c|c} 
Groups & $\mathbf{n}^{*}$ & $\begin{array}{c}\text { Patients achieving } \\
\mathbf{5} 3 \text { to NRS /VAS }\end{array}$ & $\begin{array}{c}\text { Estimate of } \\
\text { success } \pm \text { SEM }\end{array}$ & 1 Quartile & Median & Mean Time \pm SEM \\
\hline Control & 263 & $55(20,9 \%)$ & $40,9 \pm 5,5$ & 30 & $<60$ & $49,4 \pm 1,50$ \\
\hline m. PEA / u.m.PEA & 1138 & $760(66,8 \%)$ & $81,8 \pm 1,5$ & 30 & 49 & $43,6 \pm 0,50$
\end{tabular}

Test log-rank $<0,000 t$

Fig. 7. Kaplan-Meier estimate by control and PEA treated groups: distribution of improvement. The figure shows the number of observed and estimated successes at the 60th day (success = achievement of threshold $\leq 3$ on NRS/VAS). 


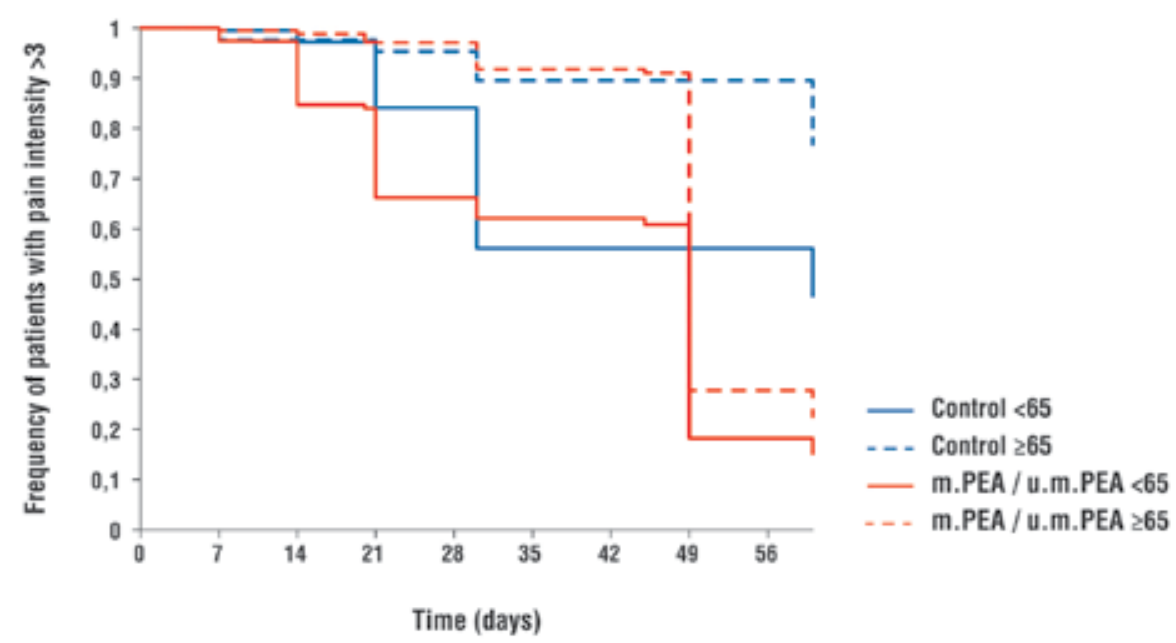

\begin{tabular}{|c|c|c|c|c|c|c|c|}
\hline Groups & Age & n. & $\begin{array}{c}\text { Patients achieving } \\
\leq 3 \text { to NRS /VAS }\end{array}$ & $\begin{array}{c}\text { Estimate } \\
\text { success } \pm \text { SE }\end{array}$ & 1 Quartile & Median & Mean Time \pm SE \\
\hline \multirow{2}{*}{ Control } & $<65$ & 220 & $47(21,4 \%)$ & $53,3 \pm 8,6$ & 30 & 60 & $45,2 \pm 2,32$ \\
\cline { 2 - 9 } & $\geq 65$ & 43 & $8(18,6 \%)$ & $23,2 \pm 7,3$ & $n s$ & $n s$ & $56,1 \pm 1,99$ \\
\hline \multirow{2}{*}{ m.PEA / u.m.PEA } & $<65$ & 699 & $442(63,2 \%)$ & $84,7 \pm 1,9$ & 21 & 49 & $39,4 \pm 0,67$ \\
\cline { 2 - 9 } & $\geq 65$ & 439 & 318 & $77,4 \pm 2,4$ & 49 & 49 & $50,1 \pm 0,44$ \\
\hline
\end{tabular}

Test log-rank $<0,000$ i

Fig. 8. Kaplan-Meier estimate by control and PEA treated groups and age: distribution of improvement in groups based on age criteria (<65 e $\geq 65$ ). The table shows the number of observed and estimated successes at the 60th day (success = achievement of threshold $\leq 3$ on NRS/VAS).

with PEA (427 patients) showed no clinical and statistical differences (42).

Serious, non-serious, or suspected adverse events related to treatment with PEA were never reported/ observed in all analyzed studies. The safety evaluation refers to the entire period of study even after the sixtieth day.

\section{Discussion}

Current analgesics are mainly based on molecules that reduce pain perception, transduction, and transmission, and modulation in neurons and/or reduce peripheral inflammation. The nature of these pharmacological targets is likely to be the principal cause of their limited success in controlling disease progression. Mounting evidence points to neuroinflammation mediated by immune cell activation, in particular mast cells and microglia, and the production of inflammatory mediators, as having a crucial role in the pathogenesis of chronic pain $(40,42,43)$. Neuroinflammation drives chronic pain via neuron-immune cell interactions $(12,13)$. Targeting the processes/molecules involved in neuroinflammation could thus lead to more effective treatment of chronic pain. The results reported in this pooled meta-analysis represent an important support to this assumption. PEA, a pro-resolving lipid signaling molecule which controls the activity of mast cells and glia, when added to ongoing standard therapies for chronic pain in patients with unsatisfactory management of pain, progressively reduces the score of pain intensity. The differences in pain reduction between the PEA-treated group and controls is statistically significant already at the first observation time (7 - 10 days of treatment). It is reinforced at later observation times, with maximal difference achieved after 60 days of treatment. The effect of PEA is easily appreciated by evaluating the mean pain score before and at the end of observational times in both groups. At basal, the control group displays a mean pain score of $6.4 \pm$ 0.1 which, although becoming lower in the middle ob- 
servations, shows a mean score of $6.5 \pm 0.5$ at T5. This clearly illustrates the difficulty in achieving a resolution of chronic pain and neuropathic pain spontaneously or with standard therapies, in the examined patients. In the PEA-treated patients the mean pain score at basal was $6.6 \pm 0.1$ and $2.9 \pm 0.1$ at T5, indicating a clear shift from pain generally considered as inducing severe interference with functioning to that causing mild functional interference (44). The Kaplan-Meyer estimate showed that after about 50 days of therapy $81.8 \%$ of PEA-treated patients achieved a pain intensity score $<3$ vs $40.9 \%$ in the control group.

Regression analysis applied to pain scores showed a marked difference in the coefficient of determination (R2) obtained in control and PEA-treated groups. A linear model in the control group explains only $1 \%$ in the response variability, while in the PEA-treated group $35 \%$ of the variability of the response data are around its mean. Moreover, the daily pain reduction coefficient is -0.015 in the control group and -0.074 in the PEAtreated group, indicating a 5 -fold more rapid reduction of pain intensity over time for PEA-treated patients.

Data obtained in the PEA-treated patients underline a progressive reduction of pain scores within the treatment period of time, supporting the supposed disease-modifying action of PEA (40). In neuropathic models of pain, PEA, besides preventing pain threshold alterations, preserves nerve morphology and prevents nerve degeneration $(38,39)$. In these studies, the neuroprotective effect of PEA was associated with a limited recruitment and activation of immune cells in the nerve as well as a reduced activation of spinal cord glia $(38,39)$. The progressive pain-relieving effect associated to neuroprotection elicited by PEA is a peculiar characteristic among analgesic agents. Antidepressants, anticonvulsants, and opioids are involved in pain perception as well as modulation on the descending pathway; however they cannot intervene in nervous tissue alterations that act as a base of chronic pain and neuropathic pain. Consequently, their action is symptomatic and the control of perception and elaboration of pain in general is limited (45). Moreover NSAIDs, frequently used to relieve symptoms in chronic inflammatory conditions associated with pain (46), seem to provide only short-term pain relief as compared to placebo $(47,48)$.

The progressive reduction of pain scores elicited by PEA confirms preclinical data showing that PEA does not induce tolerance (49). Prolonged use of analgesics such as morphine and other opioids can lead to analgesic tolerance, whereby increasing dosage is needed to maintain efficacy. Unfortunately, such dose adjustments often increase the risk of serious side effects, enabling the patient to continue analgesic therapy. Consequent$l y$, very effective analgesic drugs are difficult to use for long periods. Even though analgesic drugs continue to be widely used and accepted in the treatment of pain, their efficacy profile is less then optimal and, in addition, they may carry notable side effects, especially in the elderly, (www.who.int/healthinfo/survey/ageingde fnolder/en/), e.g., people aged 65 or older. For this reason, guidelines for management of persistent pain in the elderly suggest caution when using NSAIDs orally, keeping to the lowest dose and shortest duration possible $(50,51)$. Elderly persons taking NSAIDs should be routinely monitored for potential gastrointestinal and hepatic risks, cardiovascular and renal side effects, and drug interactions. The use of tricyclic antidepressants and antiepileptic drugs is severely limited due to poor tolerability and significant side effects (50). Opioid use also has drawbacks: they act not only on neurons but also on non-neuronal cells such as microglia, astrocytes, and mast cells, causing their activation which further promotes the development of neuroinflammation $(52,53)$. Important side effects of these therapies are, in fact, attributable to the activation of non-neuronal cells (54). PEA, in agreement with previous studies (23), and confirmed in the present meta-analysis, not only does not induce pharmacological tolerance, but is safe for patients and does not interfere with poly-drug therapies that the elderly are oftentimes subjected to $(40,55,56)$.

The approach to meta-analyses is normally oriented to calculating probabilities based on relative risk or on effect sizes. However, we believe that it is important to consider other variables such as age and gender. For this reason our pooled meta-analysis evaluated separately the efficacy of PEA in patients aged > 65 years. We must consider that although the elderly are the biggest users of analgesics, only a small number of trials designed to determine efficacy and safety of analgesics have been carried out in elderly patients $(57,58)$. Regression analysis showed that aged patients are responsive to PEA treatment similarly to patients aged $<65$ years, although the reduction of pain intensity was somewhat slower in patients aged $>65$ years. In fact, daily pain reduction in patients aged $>65$ years is equal to 1.01 vs 1.17 observed in those $<65$ years. In any case, PEA treatment was well-tolerated and no interaction with other ongoing therapy was reported.

Moreover, PEA treatment was efficacious in pa- 
tients of both genders and for chronic pain associated to a variety of pathological conditions. This finding is in line with the hypothesis that PEA controls mechanisms that are common to different conditions where chronic pain or neuropathic pain are associated. Drug therapy for the latter should ideally be based on the etiological mechanisms underlying clinical presentations of pain. However, this assumption does not exclude the possibility of developing targeted therapies to control common mechanisms that for PEA have been identified in neuroinflammatory processes mediated by the aberrant activation of mast cells and microglia. It is important to point out that PEA appears to function as an anti-inflammatory and analgesic agent with more than one "modus operandi," and to modulate the endocannabinoid system in a safer and therapeutically more efficacious way $(40,59)$. PEA may exert both receptor and non-receptor mediated effects at different cellular and tissue sites (60), suggesting that its pleiotropic action is a critical feature that adapts this molecule for the complexity of chronic pain.

The data discussed here refer to products based on micronized and ultra-micronized PEA, commercially available in Italy and several other European countries. PEA contained in this formulation is a patented, pharmaceutical compound subjected to the so-called jet micronization process $(61,62)$. This micronization and ultra-micronization process generates a crystalline structure, favoring a better pharmacokinetic process, which pharmacokinetic and pharmacodynamic properties have been recently reported $(40,63)$.

\section{Conclusions}

Chronic pain management remains a challenge for the clinician. Despite different therapeutic opportuni- ties, no more than half of patients experience clinically meaningful pain relief, which is most often partial at best (10). Among innovative therapies for treating chronic pain, PEA seems to come to the forefront owing to its high efficacy/risk ratio and lack of both tolerance induction and interference with other potential therapies for pain and/or co-morbid conditions. PEAinduced pain relief is progressive, age- and genderindependent, and not related to etio-pathogenesis of chronic pain. This supports the view that PEA controls mechanisms common to different conditions where chronic pain or neuropathic pain is associated, e.g., neuroinflammation. Neuroinflammation accompanies a variety of neurodegenerative diseases; in some (if not all) of these disorders, neuroinflammation is not only a consequence but may also be a trigger of pathology. The data reported here point to PEA as possessing intrinsic efficacy towards syndromes co-morbid with chronic pain, e.g., depression and anxiety $(64,65)$. Importantly, PEA lacks acute and chronic toxicity (23), and is not associated with gastric mucosal lesions. These characteristics have made it possible to include PEA in a new class of therapeutic agents called "Food for Special Medical Purposes" (FSMP). FSMP is a product "intended to meet the particular nutritional requirements of a person affected by a specific disease, disorder or medical condition" in order to treat or help to treat that specific condition (66). Many of these assumptions were already in the literature (67), and this meta-analysis has just clearly quantified their entity.

\section{Acknowledgments}

This study was partially supported by the Ministry of University research grant, PON "Ricerca e Competitività 2007-2013" PON01_02512.

\section{References}

1. Langley $P$, Müller-Schwefe G, Nicolaou A, Liedgens $H$, Pergolizzi J, Varrassi G. The societal impact of pain in the European Union: Health-related quality of life and healthcare resource utilization. J Med Econ 2010; 13:571-581.

2. Langley $P$, Müller-Schwefe G, Nicolaou A, Liedgens $H$, Pergolizzi J, Varrassi G. The impact of pain on labor force participation, absenteeism and presenteeism in the European Union. J Med Econ 2010; 13:662-672.

3. Harstall C. How prevalent is chronic pain? Pain Clinical Updates X, 2003; 1-4,.
4. Miller RE, Miller RJ, Malfait AM. Osteoarthritis joint pain: The cytokine connection. Cytokine 2014; 70:185-193.

5. Loeser JD, Treede RD. The Kyoto protocol of IASP basic pain terminology. Pain 2008; 137:473-477.

6. Jay GW, Barkin RL. Neuropathic pain: Etiology, pathophysiology, mechanisms, and evaluations. Dis Mon 2014; 60:6-47.

7. van Laar M, Pergolizzi JV Jr, Mellinghoff HU, Merchante IM, Nalamachu S, O'Brien J, Perrot S, Raffa RB. Pain treatment in arthritis-related pain: Beyond NSAIDs. Open Rheumatol J 2012;
6:320-330.

8. Dimitroulas T, Duarte RV, Behura A, Kitas GD, Raphael JH. Neuropathic pain in osteoarthritis: A review of pathophysiological mechanisms and implications for treatment. Semin Arthritis Rheum 2014; 44:145-154.

9. Walters ET. Neuroinflammatory contributions to pain after $\mathrm{SCl}$ : Roles for central glial mechanisms and nociceptormediated host defense. Exp Neurol 2014; 258:48-61.

10. Dworkin RH, O'Connor AB, Audette J, Baron R, Gourlay GK, Haanpää ML, Kent 
JL, Krane EJ, Lebel AA, Levy RM, Mackey SC, Mayer J, Miaskowski C, Raja SN, Rice AS, Schmader KE, Stacey B, Stanos $S$, Treede RD, Turk DC, Walco GA, Wells $\mathrm{CD}$. Recommendations for the pharmacological management of neuropathic pain: An overview and literature update. Mayo Clin Proc 2010; 85:S3-S14.

11. Nightingale $\mathrm{S}$. The neuropathic pain market. Nat Rev Drug Discov 2012; 11:101-102.

12. Mika J, Zychowska M, Popiolek-Barczyk K, Rojewska E, Przewlocka B. Importance of glial activation in neuropathic pain. Eur J Pharmacol 2013; 716:106-119.

13. Ji RR, Xu ZZ, Gao YJ. Emerging targets in neuroinflammation-driven chronic pain. Nat Rev Drug Discov 2014; 13:533-548.

14. Tiwari V, Guan Y, Raja SN. Modulating the delicate glial-neuronal interactions in neuropathic pain: Promises and potential caveats. Neurosci Biobehav Rev 2014; 45C:19-27.

15. Serhan CN, Savill J. Resolution of inflammation: The beginning programs the end. Nat Immunol 2005; 6:1191-1197.

16. Buckley CD, Gilroy DW, Serhan CN, Stockinger B, Tak PP. The resolution of inflammation. Nat Rev Immunol 2013; 13:59-66.

17. Skaper SD, Facci L, Giusti P. Mast cells, glia and neuroinflammation: Partners in crime? Immunology 2014; 141:314-327.

18. Facci L, Dal Toso R, Romanello S, Buriani A, Skaper SD, Leon A. Mast cells express a peripheral cannabinoid receptor with differential sensitivity to anandamide and palmitoylethanolamide. Proc Natl Acad Sci USA 1995; 92:3376-3380.

19. Cerrato $S$, Brazis $P$, della Valle MF, Miolo A, Puigdemont A. Effects of palmitoylethanolamide on immunologically induced histamine, PGD2 and TNFalpha release from canine skin mast cells. Vet Immunol Immunopathol 2010; 133:9-15.

20. Franklin A, Parmentier-Batteur S, Walter L, Greenberg DA, Stella N. Palmitoylethanolamide increases after focal cerebral ischemia and potentiates microglial cell motility. J Neurosci 2003; 23:7767-7775.

21. Loría F, Petrosino S, Mestre L, Spagnolo A, Correa F, Hernangómez M, Guaza C, Di Marzo V, Docagne F. Study of the regulation of the endocannabinoid system in a virus model of multiple sclerosis reveals a therapeutic effect of palmitoylethanolamide. Eur J Neurosci 2008; 28:633-641.

22. Luongo L, Guida F, Boccella S, Bellini G, Gatta L, Rossi F, de Novellis V, Maione
S. Palmitoylethanolamide reduces formalin-induced neuropathic-like behaviour through spinal glial/microglial phenotypical changes in mice. CNS Neurol Disord Drug Targets 2013; 12:45-54.

23. Esposito E, Cuzzocrea S. Palmitoylethanolamide is a new possible pharmacological treatment for the inflammation associated with trauma. Mini Rev Med Chem 2013; 13:237-255.

24. Petrosino $S$, Palazzo E, de Novellis $V$, Bisogno T, Rossi F, Maione S, Di Marzo V. Changes in spinal and supraspinal endocannabinoid levels in neuropathic rats. Neuropharmacology 2007; 52:415-422.

25. Degenhardt BF, Darmani NA, Johnson JC, Towns LC, Rhodes DC, Trinh C, McClanahan B, Di Marzo V. Role of osteopathic manipulative treatment in altering pain biomarkers: A pilot study. J Am Osteopath Assoc 2007; 107:387-400.

26. Sarchielli P, Pini LA, Coppola F, Rossi C, Baldi A, Mancini ML, Calabresi P. Endocannabinoids in chronic migraine: CSF findings suggest a system failure. Neuropsychopharmacology 2007; 32:1384-1390.

27. Ghafouri N, Ghafouri B, Larsson B, Turkina MV, Karlsson L, Fowler CJ, Gerdle B. High levels of $\mathrm{N}$-palmitoylethanolamide and $\mathrm{N}$-stearoylethanolamide in microdialysate samples from myalgic trapezius muscle in women. PLoS One 2011; 6:e27257.

28. Ghafouri N, Ghafouri B, Larsson B, Stensson N, Fowler CJ, Gerdle B. Palmitoylethanolamide and stearoylethanolamide levels in the interstitium of the trapezius muscle of women with chronic widespread pain and chronic neck-shoulder pain correlate with pain intensity and sensitivity. Pain 2013; 154:1649-1658.

29. Mazzari S, Canella R, Petrelli L, Marcolongo $\mathrm{G}$, Leon A. N-(2-hydroxyethyl) hexadecanamide is orally active in reducing edema formation and inflammatory hyperalgesia by down-modulating mast cell activation. Eur J Pharmacol 1996; 300:227-236.

30. Calignano A, La Rana G, Giuffrida A, Piomelli D. Control of pain initiation by endogenous cannabinoids. Nature 1998; 394:277-281.

31. Jaggar SI, Hasnie FS, Sellaturay S, Rice AS. The anti-hyperalgesic actions of the cannabinoid anandamide and the putative $\mathrm{CB}_{2}$ receptor agonist palmitoylethanolamide in visceral and somatic inflammatory pain. Pain 1998; 76:189-199.
32. Romero TR, Duarte ID. N-palmitoylethanolamine (PEA) induces peripheral antinociceptive effect by ATP-sensitive K+-channel activation. J Pharmacol Sci 2012; 118:156-160.

33. Romero TR, Galdino GS, Silva GC, Resende LC, Perez AC, Cortes SF, Duarte ID. Involvement of the L-arginine/nitric oxide/cyclic guanosine monophosphate pathway in peripheral antinociception induced by $\mathrm{N}$-palmitoyl-ethanolamine in rats. J Neurosci Res 2012; 90:1474-1479.

34. Romero TR, Resende LC, Guzzo LS, Duarte ID.CB1 and $C_{2}$ cannabinoid receptor agonists induce peripheral antinociception by activation of the endogenous noradrenergic system. Anesth Analg 2013; 116:463-472.

35. De Filippis D, Luongo L, Cipriano $M$, Palazzo E, Cinelli MP, de Novellis V, Maione S, luvone T. Palmitoylethanolamide reduces granuloma-induced hyperalgesia by modulation of mast cell activation in rats. Mol Pain 2011; 10:3.

36. Helyes Z, Németh J, Thán M, Bölcskei K, Pintér E, Szolcsányi J. Inhibitory effect of anandamide on resiniferatoxininduced sensory neuropeptide release in vivo and neuropathic hyperalgesia in the rat. Life Sci 2003; 73:2345-2353.

37. Costa B, Comelli F, Bettoni I, Colleoni $M$, Giagnoni $G$. The endogenous fatty acid amide, palmitoylethanolamide, has anti-allodynic and anti-hyperalgesic effects in a murine model of neuropathic pain: Involvement of $\mathrm{CB}(1)$, TRPV 1 and PPARgamma receptors and neurotrophic factors. Pain 2008; 139:541-550.

38. Bettoni I, Comelli F, Colombo A, Bonfanti P, Costa B. Non-neuronal cell modulation relieves neuropathic pain: Efficacy of the endogenous lipid palmitoylethanolamide. CNS Neurol Disord Drug Targets 2013; 12:34-44.

39. Di Cesare Mannelli L, D’Agostino G, Pacini A, Russo R, Zanardelli M, Ghelardini C, Calignano A. Palmitoylethanolamide is a disease-modifying agent in peripheral neuropathy: Pain relief and neuroprotection share a PPAR-alphamediated mechanism. Mediators Inflamm 2013; (e-Pub only)

40. Skaper SD, Facci L, Fusco M, Della Valle MF, Zusso M, Costa B, Giusti P. Palmitoylethanolamide, a naturally occurring disease-modifying agent in neuropathic pain. Inflammopharmacology 2014; 22:79-94.

41. Freitag CM, Miller RJ. Peroxisome proliferator-activated receptor agonists modulate neuropathic pain: a link to 
chemokines? Front Cell Neurosci 2014; 8.

42. Guida G, De Martino M, De Fabiani A, Canteri L, Alexandre A, Vassallo GM, Rogai M, Lanaia F e Petrosino S. La Palmitoiletanolamide (Normast ${ }^{\circledR}$ ) en el dolor neuropático crónico por lumbociatalgia de tipo compresivo: Estudio clinico multícéntrico. Dolor 2010; 25:35-42.

43. Skaper SD, Facci L. Mast cell-glia axis in neuroinflammation and therapeutic potential of the anandamide congener palmitoylethanolamide. Philos Trans $R$ Soc Lond B Biol Sci 2012; 367:3312-3325.

44. Boonstra AM, Schiphorst Preuper HR, Balk GA, Stewart RE. Cut-off points for mild, moderate, and severe pain on the visual analogue scale for pain in patients with chronic musculoskeletal pain. Pain 2014; 155:2545-2550.

45. Attal N, Cruccu G, Baron R, Haanpää $M$, Hansson P, Jensen TS, Nurmikko T; European Federation of Neurological Societies. EFNS guidelines on the pharmacological treatment of neuropathic pain: 2010 revision. Eur J Neurol 2010; 17:1113-e88.

46. Tabas I, Glass CK. Anti-inflammatory therapy in chronic disease: Challenges and opportunities. Science 2013; 339:166-172.

47. Kuijpers $T$, van Middelkoop M, Rubinstein SM, Ostelo R, Verhagen A, Koes $B W$, van Tulder MW. A systematic review on the effectiveness of pharmacological interventions for chronic nonspecific low-back pain. Eur Spine J 2011; 20:40-50.

48. Marini I, Bartolucci ML, Bortolotti F, Gatto MR, Bonetti GA. Palmitoylethanolamide versus a nonsteroidal antiinflammatory drug in the treatment of temporomandibular joint inflammatory pain. J Orofac Pain 2012; 26:99-104.

49. Wise LE, Cannavacciulo R, Cravatt BF, Martin BF, Lichtman AH. Evaluation of fatty acid amides in the carrageenaninduced paw edema model. Neuropharmacology 2008; 54:181-188.

50. Barkin RL, Beckerman M, Blum SL, Clark FM, Koh EK, Wu DS. Should nonsteroidal anti-inflammatory drugs (NSAIDs) be prescribed to the older adult? Drugs Aging 2010; 27:775-789.

51. Abdulla A, Adams N, Bone M, Elliott AM, Gaffin J, Jones D, Knaggs R, Martin D, Sampson L, Schofield P; British Geriatric Society. Guidance on the management of pain in older people. Age Ageing 2013; 42:i1-i57.
52. Sheen CH, Schleimer RP, Kulka M. Codeine induces human mast cell chemokine and cytokine production: Involvement of G-protein activation. Allergy 2007; 62:532-538.

53. Eidson LN, Murphy AZ. Blockade of tolllike receptor 4 attenuates morphine tolerance and facilitates the pain relieving properties of morphine. J Neurosci 2013; 33:15952-15963.

54. Merighi S, Gessi S, Varani K, Fazzi D, Stefanelli A, Borea PA. Morphine mediates a proinflammatory phenotype via $\mu$-opioid receptor-PKCD-Akt-ERK1/2 signaling pathway in activated microglial cells. Biochem Pharmacol 2013; 86:487-496.

55. Fusco M, Paladini A, Skaper SD, Varrassi G. Chronic and neuropathic pain syndrome in the elderly: Pathophysiological basis and perspectives for a rational therapy. Pain Nursing Magazine 2014; 3:3.

56. Varrassi G, Fusco M, Coaccioli S, Pala$\operatorname{dini} A$. Chronic pain and neurodegenerative processes in elderly people. Pain Pract 2015; 15:1-3.

57. Bayer A, Tadd W. Unjustified exclusion of elderly people from studies submitted to research ethics committee for approval: Descriptive study. BMJ 2000; 321:992-993.

58. Koponen MP, Bell JS, Karttunen NM, Nykänen IA, Desplenter FA, Hartikainen SA. Analgesic use and frailty among community-dwelling older people: A population-based study. Drugs Aging 2013; 30:129-136.

59. Maione S, Costa B, Di Marzo V. Endocannabinoids: A unique opportunity to develop multitarget analgesics. Pain 2013; 154:S87-S93.

6o. Petrosino S, luvone T, Di Marzo V. Npalmitoyl-ethanolamine: Biochemistry and new therapeutic opportunities. Biochimie 2010; 92:724-727.

61. Rao S, Song Y, Peddie F, Evans AM. Particle size reduction to the nanometer range: A promising approach to improve buccal absorption of poorly water-soluble drugs. Int J Nanomed 2011; 6:1245-1251.

62. Sareen S, Mathew G, Joseph L. Improvement in solubility of poor water-soluble drugs by solid dispersion. Int ] Pharm Investig 2012; 2:12-17.

63. Impellizzeri D, Bruschetta G, Cordaro M, Crupi R, Siracusa R, Esposito E, Cuzzocrea S. Micronized/ultramicronized palmitoylethanolamide displays supe- rior oral efficacy compared to nonmicronized palmitoylethanolamide in a rat model of inflammatory pain. J Neuroinflammation 2014; 11:136.

64. Graziottin A, Skaper SD, Fusco M. Inflammation and chronic pelvic pain: A biological trigger for depression in women? J Depress Anxiety 2013; 3:142.

65. Graziottin A, Skaper SD, Fusco M. Mast cells in chronic inflammation, pelvic pain and depression in women. Gynecol Endocrinol 2014; 30:472-477.

66. Commission Directive 1999/21/EC of 25 March 1999 on dietary foods for special medical purposes. Official Journal of the European Communities 1999; L91:29-36.

67. Paladini A, Fusco M, Coaccioli S, Skaper SD, Varrassi G. Chronic pain in the elderly: The case for new therapeutic strategies. Pain Phys 2015;18: E863-E876.

68. Assini A, Laricchia D, Belletti M, Pandolfini L, Pizzo R, Ratto S. The carpal tunnel syndrome in diabetes: Clinical and electrophysiological improvement after treatment with palmitoylethanolamide. 2010 EFNS. Eur] Neurol 2010; 17: 295-295.

69. Gatti A, Lazzari M, Gianfelice V, Di Paolo A, Sabato E, Sabato AF. Palmitoylethanolamide in the treatment of chronic pain caused by different etiopathogeneses. Pain Med 2012; 13:1121-1130.

70. Desio P. Combination of oxycodone and palmitoylethanolamide for low back pain treatment. Anestesia e Medicina critica 2011; 1:63-71.

71. Desio P. Combination of pregabalin and palmitoylethanolamide (PEA) for neuropathic pain treatment. Pathos 2010; 7:9-14.

72. Cocito D, Peci E, Ciaramitaro P, Cocito C, Merola A, Lopiano L. Short-term efficacy of ultramicronized palmitoylethanolamide in peripheral neuropathic pain. Pain Res Treat 2014; 2014:854560.

73. Parabita M, D'Amore RM, Marinosci F, Matera MG, Izzo A, Russo GA. Reduction of post stroke spasticity with palmitoylethanolamide treatment. XIV Congress of the European Shock Society. Taormina, August 31, September 2, 2011.

74. Montella S, Carotenuto A, Orefice NS, Orefice G. A double-blind, randomized, versus-placebo study of ultramicronized palmitoylethanolamide in subjects with relapsing-remitting multiple sclerosis: Preliminary results. 2014 EFNS-ENS. Eur ] Neurol 2014; 21:676. 